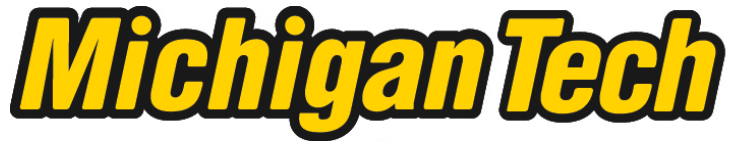 \\ Michigan Technological University Create the Future Digital Commons @ Michigan Tech
}

2015

\section{A MARKET-BASED APPROACH TO 3D PRINTING FOR ECONOMIC DEVELOPMENT IN GHANA}

Wade Aitken-Palmer

Michigan Technological University

Follow this and additional works at: https://digitalcommons.mtu.edu/etds

Part of the Growth and Development Commons, and the Mechanical Engineering Commons Copyright 2015 Wade Aitken-Palmer

\section{Recommended Citation}

Aitken-Palmer, Wade, "A MARKET-BASED APPROACH TO 3D PRINTING FOR ECONOMIC DEVELOPMENT IN GHANA", Master's report, Michigan Technological University, 2015.

https://doi.org/10.37099/mtu.dc.etds/923

Follow this and additional works at: https://digitalcommons.mtu.edu/etds

Part of the Growth and Development Commons, and the Mechanical Engineering Commons 


\title{
A MARKET-BASED APPROACH TO 3D PRINTING FOR ECONOMIC DEVELOPMENT IN GHANA
}

By

Wade Aitken-Palmer

\author{
A REPORT \\ Submitted in partial fulfillment of the requirements for the degree of \\ MASTER OF SCIENCE \\ In Mechanical Engineering \\ MICHIGAN TECHNOLOGICAL UNIVERSITY \\ 2015 \\ (c) 2015 Wade Aitken-Palmer
}


This report has been approved in partial fulfillment of the requirements for the Degree of MASTER OF SCIENCE in Mechanical Engineering.

Department of Mechanical Engineering - Engineering Mechanics

\author{
Report Co-Advisor: John Gershenson \\ Report Co-Advisor: $\quad$ Michele Miller
}

Committee Member: $\quad$ Blair Orr

Department Chair: William Predebon 


\section{Table of Contents}

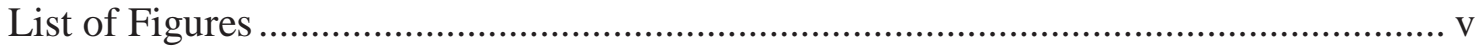

List of Abbreviations …………………………………………………………… v

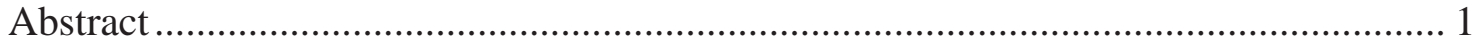

Chapter 1 Introduction ..................................................................................... 2

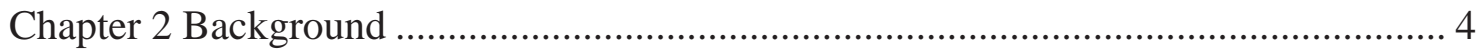

2.1 Economic Development.................................................................................... 5

2.2 Technological Advancement ....................................................................... 6

2.3 Market-Based Approach to Poverty Reduction ………......................................... 8

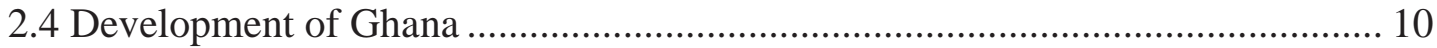

Chapter 3 Market Opportunity.................................................................................... 12

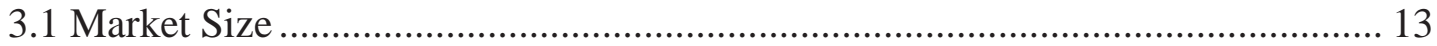

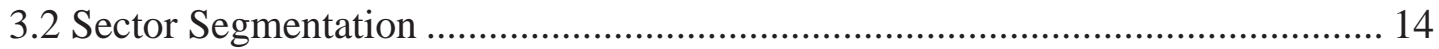

3.3 Wealth Creation Ecosystem ................................................................................ 14

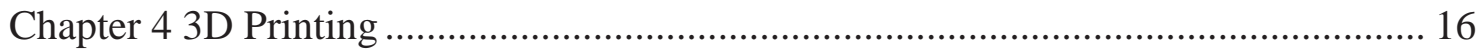

4.1 Additive Manufacturing and 3D Printing History …………............................... 16

4.2 Importance of 3D printing ................................................................................. 17

4.3 Additive Manufacturing and 3D Printer Market.................................................... 19

4.4 Personal 3D Printer State of the Art ................................................................ 20

4.5 Barriers to Adoption ...................................................................................... 21

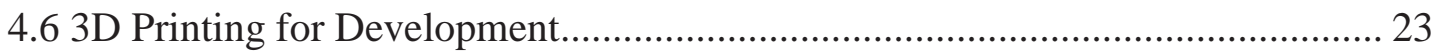

Chapter 5 A 3D Printing Ecosystem for Ghana.............................................................. 24

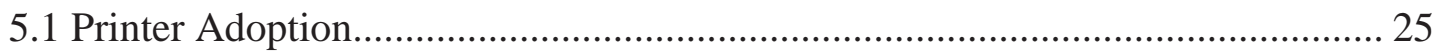

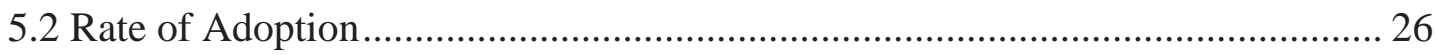

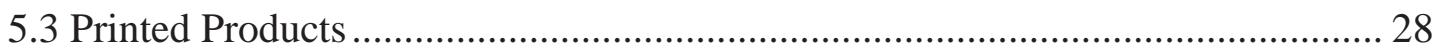

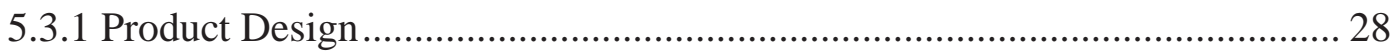

5.3.2 Direct Part Production................................................................................... 30

5.4 Market-Oriented Ecosystem …………………………..................................... 31

5.5 Location of Individuals and Institutions ................................................................. 35

Chapter 6 Implementation of 3D Printing …………………........................................ 36

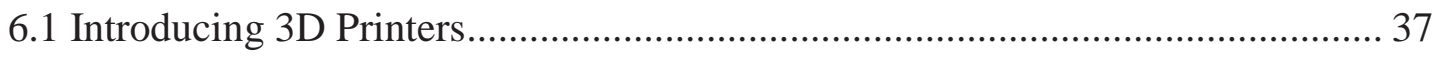

6.2 Introducing Printed Products ............................................................................. 39 


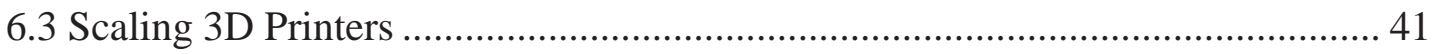

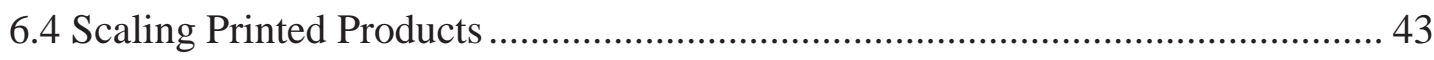

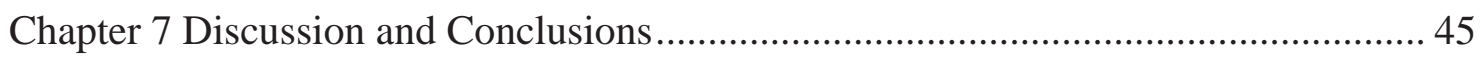

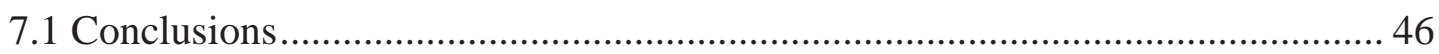

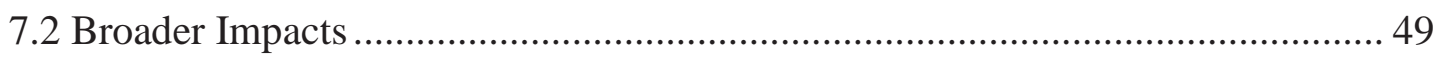

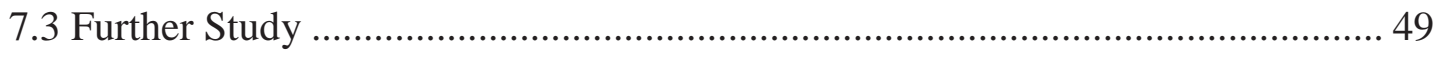

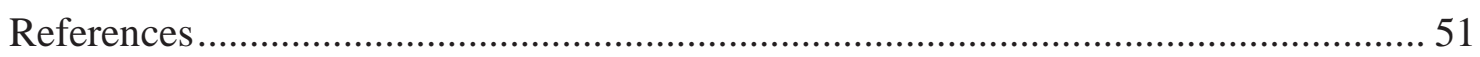




\section{List of Figures}

Figure 1.1: Map of Ghana

Figure 5.1: Diffusion of Innovations Model

Figure 5.2: Hype Cycle for 3D Consumer Printing

Figure 5.3: Innovation Matrix

\section{List of Abbreviations}

3D4D: 3D for Development

AM: Additive Manufacturing

ABS: Acrylonitrile Butadiene Styrene

ATT: Agriculture Technology Transfer

BoP: Bottom of Pyramid

CAD: Computer Aided Design

CEO: Chief Executive Officer

FDM: Fused Deposition Modeling

GDP: Gross Domestic Product

GNI: Gross National Income

HDPE: High Density Polyethylene

ICT: Internet Communication Technology

MNC: Multi-National Corporation

PET: Polyethylene Terephthalate

PLA: Polylactic Acid

SLA-1: Sterolithography Apparatus 1

SME: Small and Medium Enterprise

STL: Stereo Lithography

USAID: United States Agency for International Development 


\begin{abstract}
The purpose of this report is to create the foundation for further study of a market-based approach to 3D printing as an instrument for economic development in Ghana. The delivery of improved products and services to the most underserved markets is needed to spur economic activity and improve standards of living. The relationship between economic development and the advancement of technology is considered within the context of Ghana. An opportunity for market entry exists within both the bottom of the economic pyramid and the mid-segment market. 3D printing (additive manufacturing) has proven to be a disruptive technology that has demonstrated an ability to expedite the speed of innovations and create products that were previously not possible. An investigation of how 3D printers can be used to create improved products for the most underserved markets within Ghana is presented. Questions are asked to elucidate how and when adoption of 3D printers and 3D printed products may occur in the future. Based upon the existing barriers to adoption, 3D printing technology must improve before widespread adoption will occur in Ghana.
\end{abstract}




\section{Chapter 1 Introduction}

As a Peace Corps Master's International student in Mechanical Engineering, I spent over two years in Ghana. Ghana is located in West Africa and surrounded by Togo, Burkina Faso, Côte d'Ivoire, and the Gulf of Guinea, see (Figure 1.1). The country is diverse with 75 ethnic groups and more than 250 languages and dialects spoken (www.ghanaembassy.org). I worked as a physics teacher at Abor Senior High School. The town of Abor is located in the southeast corner of the Volta Region in Ghana. The Eve people are the predominant ethnic group in the southern Volta region, while Anlogbe is the main dialect spoken in the Keta Municipal District. The district is characterized by farming and fishing in and around the brackish Keta lagoon. 


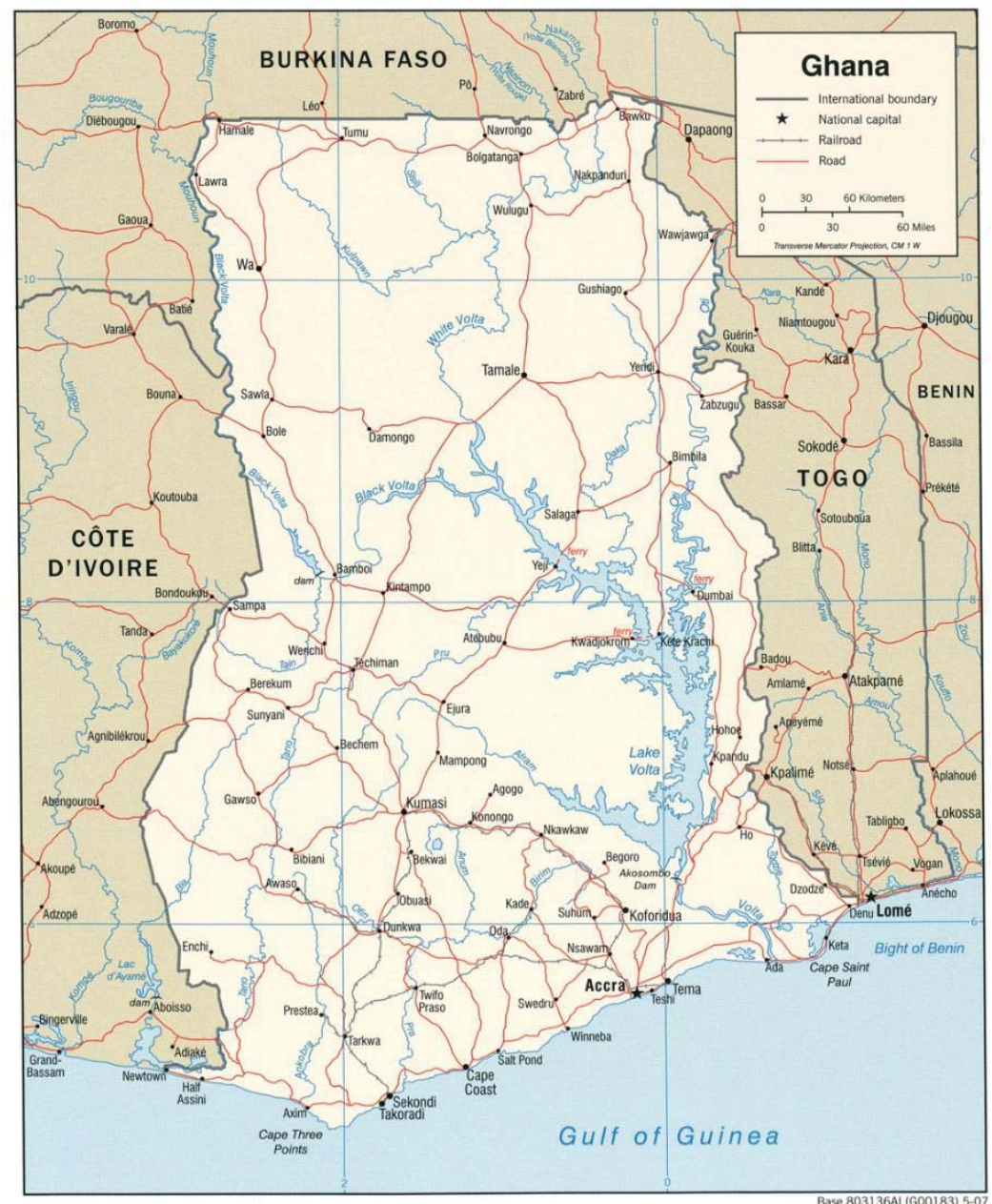

Figure 1.1: Map of Ghana (MapCruzin, 2007)

After two years of teaching, I moved to Tamale, capital of the Northern Region, to work on the USAID-Ghana Agriculture Technology Transfer (ATT) project. The ATT project is under the Feed the Future initiative within the economic growth office of USAID. The primary goal of the ATT project was to initiate economic growth in the northern three regions of Ghana by increasing agriculture production through the introduction and implementation of appropriate and affordable technologies. 
Fertilizer applicators, rice paddy seeders and other agricultural technologies that were being implemented were often made of plastic. Many agricultural technologies were made of plastic because of low-cost, light-weight and resistance to corrosion from moisture and fertilizer. There was a need to design and create prototypes to improve upon existing technologies that were available. The absence of plastic replacement parts for existing technologies and the inability to create plastic prototypes during the design process led me to wonder about the role of 3D printers.

The motivation for this report was derived from the need to design and develop improved agricultural products that could be used to increase production and lead to economic growth and food security in northern Ghana. After studying the successes and failures of development approaches and technologies from the past, a market-based approach was selected for the implementation of 3D printers. A market-based approach relies upon success with end users and customers to determine the value of a product, service, or technology. The pull of the market allows firms to design for a specific market and use market feedback to continuously improve products. The purpose of this report is to create the foundation for further study of a market-based approach to 3D printing as a means of economic development in Ghana.

\section{Chapter 2 Background}

Economic development theories to address poverty continue to be debated. Most agree that the advancement of technology is a direct stimulus for economic growth and poverty reduction. A need for technologies that are locally appropriate for 
underserved markets exists; however only a few institutions are designing and manufacturing products focused on that market. Over time, development approaches have evolved and polemics by many economists have endured. The history of Ghana since its independence is presented to demonstrate the effects of prevailing development approaches. Reviewing the social and historical conditions that have led to the current market-based approach is essential in both understanding its merits and avoiding the pitfalls of its predecessors.

\subsection{Economic Development}

Poverty is a fundamental global concern that directly affects the daily lives of individuals and societies as a whole. Three predominant schools of thought among developmental economists guide the discourse on how to approach poverty. The first is the supply-side theory, championed by Sachs (2005) who argues that poor individuals and countries suffer from a poverty trap and significant investments of capital and interventions must be introduced. The second school of thought is the demand-side theory, defended by Easterly (2006) who posits that aid does more harm than good. According to Easterly (2006), individuals respond to incentives and searchers can only pull themselves out of poverty through piecemeal solutions. Third is the corruption theory, supported by Acemoglu and Robinson (2012) who defend the position that corruption is the leading reason that poor nations are failing economically. Predatory governments and those in power embezzle financial windfalls and generally fight to uphold the oligarchy making the conditions almost impossible for those who want to pull themselves out of poverty (Banerjee and Duflo, 2011). It is probable that all three 
theories are correct to a degree and offer insights when addressing poverty-related change. Other famous developmental economists, including Collier, Yunus, Moyo, Sen, Banerjee and Duflo, offer varied approaches to poverty reduction (e.g. Collier, 2007; Yunus, 2003; Sen, 1999; Moyo 2009; Banerjee and Duflo, 2012). The discourse on developmental economics helps shape strategic decisions made by policy makers and opinion leaders.

Ferguson (1990) states that individuals who zealously purport their idea of development as inherently correct is problematic. It is important to question the meaning and reasons behind the concept of development. Few questions have received as much attention from the social sciences as what are the fundamental determinants of comparative development (Michalopoulos, 2012).

Differences in living standards throughout the world can be attributed to divergences in long-term economic growth rates (Barro and Sala-i-Martin, 2004). Despite the fact that the terms economic growth and economic development are often used interchangeably, the two terms refer to fields that have distinct differences in their underlying objectives. Economic growth focuses on market productivity and increasing gross domestic product (GDP) while economic development focuses on improving human welfare through economic activity (Perkins et al., 2006). Polak (2008) contends that it is a myth that national per capita economic growth will end poverty, and instead he suggests that national financial gains alone will continue to bypass poor people. 


\subsection{Technological Advancement}

Technological advancement is inexorably linked to economic growth and development. Most technological advancements are made by small adjustments that adapt to local circumstances and subtly improve a particular process (Comin et al., 2010). Economic and technological differences between countries imply that knowledge is not freely transferrable across borders, rather advancement is affected by social, cultural, and environmental factors (Stiglitz and Greenwald, 2014). Three primary conditions are necessary for a society to be technologically creative - 1) resourceful individuals that want to control their physical environment, 2) economic and institutional incentives for innovators, and 3) social conditions that allow for diversity and tolerance (Mokyr, 1990).

Yunus (2007) presents two possible futures that will result from technology advancements. One future results in further stratification of socioeconomic conditions because the ability to compete becomes even more unattainable for marginalized populations when advancements in technology are not readily available to all. The second scenario is one in which technology is inclusive and spreads quickly to economically inactive areas of the globe so quickly that the latent potential of populations are realized. The second scenario presents technology as a leveling mechanism that allows full participation in the global economy (Yunus, 2007). 
Technological history must be considered when determining how technology advancement will occur in the future. Correlations exist between the current wealth of nations and the technologies that those same countries developed as early as 1000BC (Comin et al., 2010). The technology historian, Edgerton (2007), stresses that viewing technologies through a user-centric lens as opposed to an innovation-centric lens allows for a greater understanding of why most technologies fail and others become ubiquitous. The distinction emphasizes how technologies were adopted and used by people in relation to all other innovations present at a particular time instead of the innovation itself.

\subsection{Market-Based Approach to Poverty Reduction}

Development and poverty reduction strategies have evolved over the past century. Development initiatives began in the early twentieth century when the British government implemented infrastructure projects through its Colonial Development Act. Following World War II, the Bretton Woods conference was held in 1944 between Allied leaders to create a framework to re-establish political and economic stability (Moyo, 2009). The United States' Marshall Plan for reconstruction guided development initiatives through the 1950s, which spurred the idea of design for development (USAID, 2012). The big push model of development guided the 1960s. The road to modernization was believed to be through industrialization and large scale investments. After governments defaulted on many of the loans given during the 1960s, the International Monetary Fund instituted a period of structural adjustments in the 1970s. As a result, many countries experienced hardships accompanied with an era 
of austerity in the late 1970s and early 1980s (Moyo, 2009). Backlash from big push initiatives and conditions experienced in the 1970s led to Schumacher's book Small is Beautiful. Schumacher was influenced by Gandhi's criticisms of modern civilization and beliefs in village-based economics (Ishii, 2001). Schumacher (1973) demonstrated how an intermediate technology could fill the gap between an unaffordable $£ 1000$ technology and a $£ 1$ indigenous technology. The appropriate technology movement emphasized local, small-scale, decentralized technologies, and was derived from many of Schumacher's ideas.

The debts of emerging-market countries continued to amass during the 1980s, totaling $\$ 1$ trillion by the end of the decade. The debt crisis, combined with the economic policies of the Reagan and Thatcher governments required countries to service their debts, which led to a reversal of net flows of money. As a result, the 1980s were a relatively dormant time in international developmental projects. Policy leaders of the 1990s believed that poor governance was the primary cause of fiscal irresponsibility and that democracy was the answer. The hardships on the African continent returned to the public's consciousness through the 2000s, and experienced a renewed resurgence of attention from the international community. (Moyo, 2009).

Pralahad (2004) presented the world's poorest people as consumers that should be engaged within the global economy. Pralahad (2004) discusses business models that target the demographic of consumers at the bottom of the economic pyramid, meaning those living on less than US \$2 per day in local purchasing power parity. The phrase bottom of the pyramid (BoP) was first used by Franklin D. Roosevelt in 1932, however 
the phrase has experienced a renewed resurgence to describe members of the most underserved markets (Mason et al., 2013). Similar to development in general, and technology in particular, the role of businesses for poverty reduction has evolved. Businesses were previously believed to be a cause of global poverty. A shift in thinking has led many to believe that businesses and a well-functioning market are essential to increasing economic activity for underserved markets. Some businesses are now beginning to refine their approach to fit and further support the goals of development. Businesses have begun to design for a specific market instead of solely designing to solve technical problems. After limited successes and extensive failures of many previous efforts to alleviate poverty, a market-based approach to poverty reduction continues to be a common strategy.

\subsection{Development of Ghana}

Ghana, since independence, provides an example of an African country that exhibits the evolution of economic development theories, technological advancement and business-centered approaches to development. Ghana, presented as a case study, demonstrates how the evolution of development strategies affect both individuals and the country as a whole. Prior to independence, Ghana was perceived as a colony that offered a great deal of potential compared to Great Britain's other colonies. Ghana had the most advanced education system of all African colonies at the time, a prosperous farming community, and a well-functioning economy (Meredith, 2005). 
Ghana was the first African colony to elect its own president, Kwame Nkrumah, and to gain independence from colonization in1957. Nkrumah was heralded as a charismatic leader full of hope and inspiration for both Ghana and the continent of Africa as a whole. Nkrumah dreamt of a Pan-African entity that would unite the continent with Ghana at the forefront. Nkrumah committed portions of Ghana's national resources to his vision of a Pan-African state. Nkrumah envisioned Ghana as a modern centralized state with large-scale industries and mechanized agriculture (Nayer, 2000). Large-scale projects were initiated throughout the country including capital intensive agriculture projects, the Akosombo hydroelectric dam, and the Tema Port. Representative of the big push views of development at the time, many large scale projects had limited success (Easterly, 2002).

Despite the promise of independence and significant financial backing, aspects of Nkrumah's presidency began to falter. Debt, mismanagement, corruption, cronyism, inflation, and Nkrumah's authoritarian leadership style ultimately created adversaries and led to unrest. A coup was staged in 1966, and Nkrumah was overthrown and exiled from the country (Nayer, 2000). Emblematic of many Sub-Saharan African (SSA) countries of the time, political instability ensued through the 1970s and 1980s with four additional coups d'état. As a result, there was overall economic contraction, which directly correlates with increased poverty (Easterly, 2001). Intermediate technology enterprises began to arise in Ghana throughout the world in the 1970s and 1980s. By 1983, Ghana experienced a full economic crisis and with periods of severe food shortages and hyperinflation. Most intermediate or appropriate technology enterprises 
in Ghana and around the world folded due to the inability to be economically sustainable by generating a profit.

Policies were implemented during the late 1980s and early 1990s that began to restore economic stability within the country (Nayer, 2000). The economy of Ghana continued to grow until it became a middle income country in 2010. The transition from a least developed country to a middle income country indicates a higher gross national income and means that it is now classified differently among international development institutions. Ghana's highest growth segments in 2011 were mining and quarrying (206.5\%), construction (20\%), trade (17.9\%), Internet communication technologies (ICT) (17\%), and manufacturing (13\%) (Frempong, 2012).

\section{Chapter 3 Market Opportunity}

The profit potential at the base of the economic pyramid is well documented, yet only a few companies have found success and realized the potential (Landrum, 2007). It is necessary to segment the market to be able to focus on specific market opportunities. The determination of sector sizes is important when calculating projected impact and profits. Once sufficient analysis of the markets has occurred, a more tangible market opportunity may be understood. After the market opportunity is established, an enterprise may begin to mold an implementation strategy. 


\subsection{Market Size}

Segmenting the world by household income creates a pyramidal shape.

Households with the largest income create the smallest percentage of people at the top of the pyramid while those with the lowest incomes constitute the largest number of people at the bottom of the economic pyramid. The World Resources Institute released a publication, in 2007, titled The Next 4 Billion Market Size and Business Strategy at the Base of the Pyramid. An estimated 4 billion people create the base of the economic pyramid, with incomes of less than $\$ 3,000$ in local purchasing power. The global market for those with household income less than $\$ 3,000$ is valued at $\$ 5$ trillion a year. Those with incomes between $\$ 3,000$ and $\$ 20,000$ constitute a 1.14 billion person global mid-market population segment, valued at $\$ 12.5$ trillion annually (WRI, 2007).

Africa's market with annual household incomes less than $\$ 3,000$ comprise $71 \%$ of the total population at 486 million people, and is valued at \$429 billion (WRI, 2007). The SSA consumer market is expected to be worth $\$ 1$ trillion by 2020 (Hatch et al., 2011). There are 10.8 million Ghanaians, $71 \%$ of the total population, who are considered economically active. Of the economically active people in Ghana, 86\% are employed by the informal sector. Income segments among the base of the economic pyramid are often further segmented below $\$ 3,000$ annually by $\$ 500$ increments to gain further insights into spending habits. A general paucity of data on the informal sector and the most underserved markets makes it more difficult to make informed strategic decisions. 


\subsection{Sector Segmentation}

Households with an income of less than \$3,000 have consistent spending habits. Seven major sectors characterize bottom of the pyramid markets: food, housing, energy, transportation, health, information communication technology (ICT), and water. The largest household expenditures are on food. Housing expenses typically remain constant while transportation and ICT are growing rapidly. Spending per income segment and sector differ by country, region and urban or rural populations. Markets often remain underserved due to companies' limited experience creating viable business models (WRI, 2007). The most well represented sectors by percentage of economically active people in Ghana are agriculture (45.5\%), wholesale and retail (12.3\%), manufacturing (8.9\%) and transportation (6.9\%) (Ghana Statistical Service, 2010). Sector segmentation should occur to focus on specific strategies for entry.

\subsection{Wealth Creation Ecosystem}

Most scholars have surpassed the bottom-up and top-down debate regarding development strategies and have agreed that the most appropriate strategy for a given scenario is context-dependent (O'Toole, 2004). The remaining debate is how to synthesize the insights and perspectives of both approaches to formulate a coherent tactic to benefit all stakeholders. The unmet needs of underserved markets result in households paying higher prices for basic goods and services compared to wealthier demographics (WRI, 2007). A market-based approach to poverty reduction allows governments to concentrate on creating a strong business environment while businesses identify new market opportunities (WRI, 2007). 
Similar to development strategies, innovation theory has evolved. Conventional innovation theory used a top-down approach where luxury goods are initially available to a limited number of people and as efficiency improves while economies of scale are applied, versions can be sold to the masses at a lower price. The top-down theory of innovation was later challenged, during the information age, when disruptors who used a bottom-up approach became more prevalent (Downes and Nunes, 2014). Downes and Nunes (2014) claim that there is a new era of big bang disruption where new market disruptors attack not just from the top, the bottom or the side but from all directions. Combining development and innovation theories, business may redefine markets and begin to understand how their enterprise may fit within a market and capitalize off a potential market opportunity.

The World Resource Institute offers four broad strategies for enterprises operating in the bottom of the economic pyramid: focusing on unique products and services, localizing value creation, enabling access to goods and services, and unconventional partnering. The consulting firm, Accenture, offers seven key steps to build a business in SAA that follows a progression of questions that must be asked when developing an implementation strategy. The first three steps include market research, value proposition, and market entry strategy. The last four steps are during the execution phase, which includes questions related to sourcing, manufacturing, distribution, and marketing and promotion (Hatch et al., 2011). A management team must target a specific opportunity and execute strategic decisions to be successful in an underserved market. 


\section{Chapter 4 3D Printing}

3D printing has the potential to disrupt existing markets and to capitalize off of market opportunities. The term 3D printing is often used interchangeably with additive manufacturing (AM) and typically implies the usage of low end printers. 3D printers have the ability to transform the methods of production and the means of doing business by changing how things are made. 3D printing technology has improved over the past 25 years and has led to increased public awareness and improved printers. As the technical, social and economic barriers to adoption erode, there are increased possibilities for market penetration and impact.

The Wohlers Associates is an industry consulting firm that releases the Wohlers Report annually, which is widely considered the most important trade publication in 3D printing and additive manufacturing (www.3Dprintingindustry.com). Much of the information contained within Chapter 4 is derived from the Wohlers Report 2013 Additive Manufacturing and 3D Printing State of the Industry Annual Worldwide Progress Report.

\subsection{Additive Manufacturing and 3D Printing History}

Additive manufacturing (AM) is a manufacturing technique that continuously adds material, layer by layer, to vertically construct three-dimensional solids. Additive manufacturing differs from traditional subtractive manufacturing processes that subtract material away from a solid leaving the desired shape (Huang et al., 2015). Commercial additive manufacturing began in 1987 when 3D systems released the first commercially 
available AM system, the Stereo Lithography Apparatus - 1 (SLA-1). The SLA-1 solidified layers of polymers with a laser. The first commercially available non-stereo lithography system was released in 1991 when Stratasys introduced the first fused deposition modeling (FDM) machine. FDM is an AM technique that extrudes layers of thermoplastic materials to form a solid. Throughout the 1990's and 2000's a myriad of new AM processes were developed (Wohlers, 2014). Each AM technique has advantages and disadvantages depending on the intended use of the printer. The fused deposition modeling (FDM) process is the most commonly used technique among lowend 3D printers, and this paper will assume the use of a FDM process unless otherwise noted.

\subsection{Importance of 3D printing}

Technology is assessed by its capacity to disrupt existing markets and its potential economic impact (Hattingh et al., 2012). The simple difference between traditional subtractive manufacturing and additive manufacturing is the ability to transform the interaction between producers, consumers, and the services provided (Holmstrom and Partanen, 2014). Bits (digital information) can now be directly converted to atoms (physical objects). Some believe 3D printing is capable of disrupting the nature of professions, labor markets, and supply chains while creating a shift in trade and geopolitics. 3D printing is said to have the capacity to initiate the newest industrial revolution (Anderson, 2012; Berman 2012). 
Additive manufacturing excels at producing small complex parts at low volumes while traditional manufacturing surpasses AM in the ability to produce high volume parts. The build rates of AM are slower than the time required per part to manufacture products through traditional means. AM eliminates the need for tooling and can compete on cost and delivery speed with products that have short production runs. AM has been used extensively for years in prototyping, visual aids, and presentation models because of the ability to create new products faster and cheaper than other production processes (Wohlers, 2013). AM becomes increasingly competitive when considering entire product life-cycle costs (Lindemann et al., 2013).

In the 1990s, there was a shift from mass production to mass customization in both manufacturing and service industries. Companies needed to be able to both mass produce and individually customize goods and services to cater to customers' individual demands in order to remain competitive (Pine II, 1993). Mass customization often utilizes pre-assembled parts that often rely on a high degree of supply chain integration (Berman, 2012). 3D printing simplifies the ability to customize products and enables designers to create products that are not possible by traditional manufacturing processes. 3D printing has the ability to change the material gradient with varying strength properties throughout a single part. For example, a pulley could be created with greater strength near the hub and rim to increase longevity and reduce wear (Huang et al., 2015). 
Innovations and adaptations will occur at a faster rate where AM is appropriate, resulting in improved products that reach consumers cheaper and faster. Manufacturing currently constitutes $15 \%$ of the global economy at $\$ 10.5$ trillion. If additive manufacturing is able to disrupt $1 \%$ of the manufacturing market there is a $\$ 105$ billion opportunity (Wohlers, 2013).

\subsection{Additive Manufacturing and 3D Printer Market}

Wohlers Associates conducted a survey in 2012 to determine the industries served by manufacturers of professional grade AM systems. Consumer products/electronics constitutes $21.8 \%$ of the applications of AM in the market. The medical and dental industry experienced growth in 2012 and reached 16.4\% (Wohlers, 2013).

Another survey was conducted to determine how AM parts are being used. Product design uses for AM include prototyping, fit and assembly, visual aids, and presentation models, which collectively constitute the largest percentage, $37.4 \%$, of the overall applications for AM. The use of AM as a complementary technology to traditional manufacturing through the creation of patterns for metal casting, tooling components, and patterns for prototyping tooling creates $26.9 \%$ of applications (Wohlers, 2013).

Personal 3D printers that sell for less than $\$ 5,000$ only represented 6.5\% of the total AM market in 2012, nonetheless averaged a 346\% growth rate per year from 2008 to 2011. The growth rate of personal printers slowed to a $46.3 \%$ increase in 2012, 
which may be attributed to the early markets of innovators and early adopters approaching a level of saturation. The personal printer market primarily consists of hobby enthusiasts and aspiring engineers as opposed to industry professionals (Wohlers, 2013). The personal 3D printer, with an average selling price of $\$ 1,124$ in 2012, does not meet the quality standards required for most product development and manufacturing organizations. There is a significant gap in the price, quality, and capabilities of industrial grade printers compared to personal printers, with average selling prices in 2012 being $\$ 79,480$ and $\$ 1,124$ respectively. The gap in the quality and price of printers exemplify the gap in the printing requirements between the maker and manufacturing communities. As the quality of personal printers increase there will be a transition and an increased prevalence of personal printers in the professional market space (Wohlers, 2013).

\subsection{Personal 3D Printer State of the Art}

The low-cost personal 3D printer category consists of printers that cost less than $\$ 3,000$. The reduction in the price of low cost 3D printers is attributed to the original RepRap open source design that was introduced in 2006. Designers from Bath University made the RepRap printer design and source code available to the public (Wohlers, 2013). As a result, the price of personal printers dropped 90\% from 2009 to 2013 (McKinsey, 2013). Existing 3D printers are classified by having either open source or proprietary hardware and software. The two primary 3D printer designs are Cartesian and deltas. Cartesian models have three rails along the $\mathrm{x}, \mathrm{y}$, and $\mathrm{z}$ axes, while the delta models have three vertical rails that connect to the extruder via universal 
joints. Cartesian designs are simpler to operate and repair from a software and mechanical perspective, while deltas are generally able to move and build faster.

Cross referencing multiple 3D printing websites, eight of the highest rated lowcost 3D printers on the market are the LulzBoltz TAZ 5, FLASHFORGE Creator Pro, Ultimaker 2, Makergear M2, Zortrax M200, Rostock MAX, Mendel 90, and the Kossel. A number of printing parameters should be taken into consideration when purchasing a 3D printer. Four commonly compared metrics are price, print volume, minimum layer height and maximum print speed. The above printers range in price from $\$ 2,200$ to $\$ 600$. The print volumes range from 20,500 to 7,400 cubic centimeters. The accuracy of a part's build is partially dependent upon the minimum layer height, which ranges from 20 to 150 microns. The maximum print speed for the extruder of the printers is between 60 and 320 millimeters per second. Other parameters that are taken into account when purchasing a printer are reliability, customer service, the printer support, filament materials, running expenses, and the ease-of-use.

\subsection{Barriers to Adoption}

3D printing is an intricate balance between software, hardware, and materials (Mertz, 2013). Existing low-cost printers and open-source software have multiple barriers to entry, which limit adoption for the average consumer. The print quality and reliability has improved, however, most printers have only made incremental improvements from the original RepRap design. Most small startup groups lack the combination of expertise in industrial design, mechanical engineering, electronics, and software integration that is required to substantially redesign a 3D printer. As a result, 
limited revolutionary innovations have occurred in the personal printer segment. The cost of commercial industrial grade printers are prohibitive for most individuals and many companies. The low cost personal printers are affordable to many but often lack the overall quality requirements for more extensive adoption. "Personal 3D printers are among the least reliable devices that a consumer can buy for home use" (Wohlers, 2013, p. 113). Even with an average selling price of $\$ 1,124$, the cost of low-end printers may be prohibitive for large segments of the market within emerging economies.

The software used for computer-aided design (CAD), slicing, and printing have learning curves and are only as effective as the user's ability. Most personal 3D printer startup companies have neglected the importance of software design, while existing open source software programs lack consistency (Wohlers, 2013).

The hardware used in open-source printers is also relatively complex to assemble and open source designs require microcontrollers to be manipulated with firmware. Manufacturing a 3D printer is complex and it is difficult to maintain quality while keeping costs down (Wohlers, 2013).

Despite the fact that a multitude of materials are used in 3D printing, acrylonitrile butadiene styrene (ABS) and polylactic acid (PLA) remain as the primary materials that are utilized regularly among low-cost personal printers. High density polyethylene (HDPE) and polyethylene terephthalate (PET) offer alternatives for recycled filament. Unfortunately, the practical applications of products made solely 
from ABS, PLS, HDPE, and PET are limited. The proliferation of plastic products evokes environmental concerns by many and must be taken into consideration

3D printers have experienced a raised level of public consciousness and the expectations of customers are likely to be similar to the consistency found in consumer electronics. If expectations are not met, potential customers may become disillusioned with the 3D printing industry (Wohlers, 2013). Some believe personal 3D printers will be present in every household, though others doubt the practicality of household use.

\subsection{D Printing for Development}

In 2011, Thomas Birchnell was alarmed by the lack of examples of 3D printing being used as a catalyst for development initiatives. Birtchnell (2014) then initiated a 3D4D (3D printing for Development) challenge that was a competition created for 3D printing innovators to develop scalable solutions for development issues. Despite increased awareness, Birchnell's book remains one of the few texts that discusses 3D printing for development purposes. Birchnell's (2014) promise of 3D printers for development at the press of a button should be tempered with the realities of the state of the art of low-cost personal printers.

Technical barriers continue to limit current low-cost personal printers' ability to deeply penetrate the most underserved markets. Nevertheless, existing printers can serve as a vehicle to test the existing capabilities of printers under local conditions. Market testing must occur to determine the functionality of existing 3D printers, and lessons may be learned from testing to determine how to overcome the barriers to adoption. One can assume that the cost, quality, and technical capabilities of 3D 
printers will improve over time. If 3D printers are going to change global production networks, stimulate economic development, and improve the livelihoods of many, it is important to determine how different aspects of a 3D printing ecosystem might interact.

\section{Chapter 5 A 3D Printing Ecosystem for Ghana}

To be on the frontier of the 3D printing market opportunities in emerging economies, it is necessary to ascertain when adoption might occur, by whom, what type of products might be created, and in what locations. Ghana, as a Middle Income Country that has experienced economic growth over the past decade, and is well positioned to be a regional leader in 3D printing. The people within Ghana's burgeoning information communication technology and technical start-up culture appear to have the knowledge capital required to become innovators and early adopters of 3D printers. A successful 3D printing ecosystem in Ghana will require widespread printer adoption. The rate of adoption is dependent on the technology readiness levels of 3D printers within the context of Ghana.

Before determining which printers are most appropriate, it is important to determine the intended purpose of the printed products. Products printed for product design have different requirements than products printed for consumer use. After the use of printed products is decided, it can be determined who is well suited for 3D printing within a market oriented ecosystem. Next, the most appropriate location of individuals and enterprises may be determined by analyzing characteristics of different locations. 


\subsection{Printer Adoption}

3D printers will likely follow the same adoption trends that have occurred for other, similar technologies. There is not a built in demand for a technology itself, rather there is a demand for goods and services that a piece of technology can produce (Moykr, 1990). 3D printers must be able to demonstrate a consistent ability to produce a good or service before adoption will occur. The diffusion of innovations occur through the diffusion of innovations model, also known as the technology adoption lifecycle (Figure 5.1). The model consists of a bell curve comprised of innovators, early adopters, early majority, late majority, and laggards (Rogers 2003).

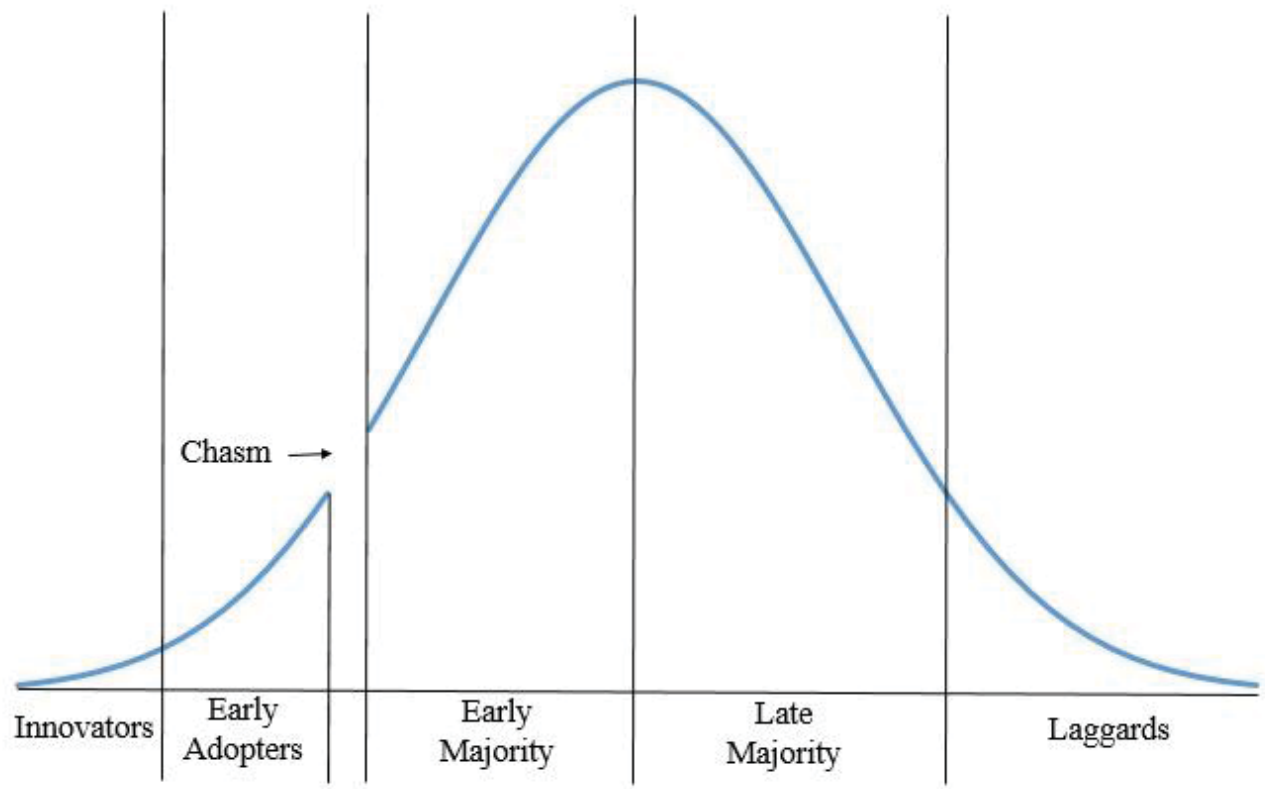

Figure 5.1 Diffusion of Innovations Model (Adapted from Rogers, 2003) 
Moore (2014) asserts that there is a disassociation or gap between each group. The marketing strategy required for each group is different than the strategy that was successful for the group to the left. Each group must market the technology in a different manner to be successful. A chasm exists once the visionary market is saturated and the pragmatists are reluctant to adopt the new technology until the technology has proven its ability to increase production. Crossing the chasm is the most difficult part of the technology adoption life-cycle and business using 3D printers must find niche market to serve (Moore, 2014).

\subsection{Rate of Adoption}

Gartner, a technology consulting firm, stated that consumer 3D printing is currently at the peak of inflated expectations on the hype cycle (Figure 5.2) and estimates that it will be five to ten years before consumer 3D printing reaches widespread adoption (www.gartner.com). Extensive technology diffusion research has contributed to a better understanding of human behavior change related to technology (Rogers, 2003). Rogers (2003) outlines A Model of Five Stages in the InnovationDecision Process. Consumer behavior and adoption dynamics should be taken into account when considering adoption strategies for 3D printers. Diffusions occur within a social system that can facilitate or impede the adoption of new technologies. 


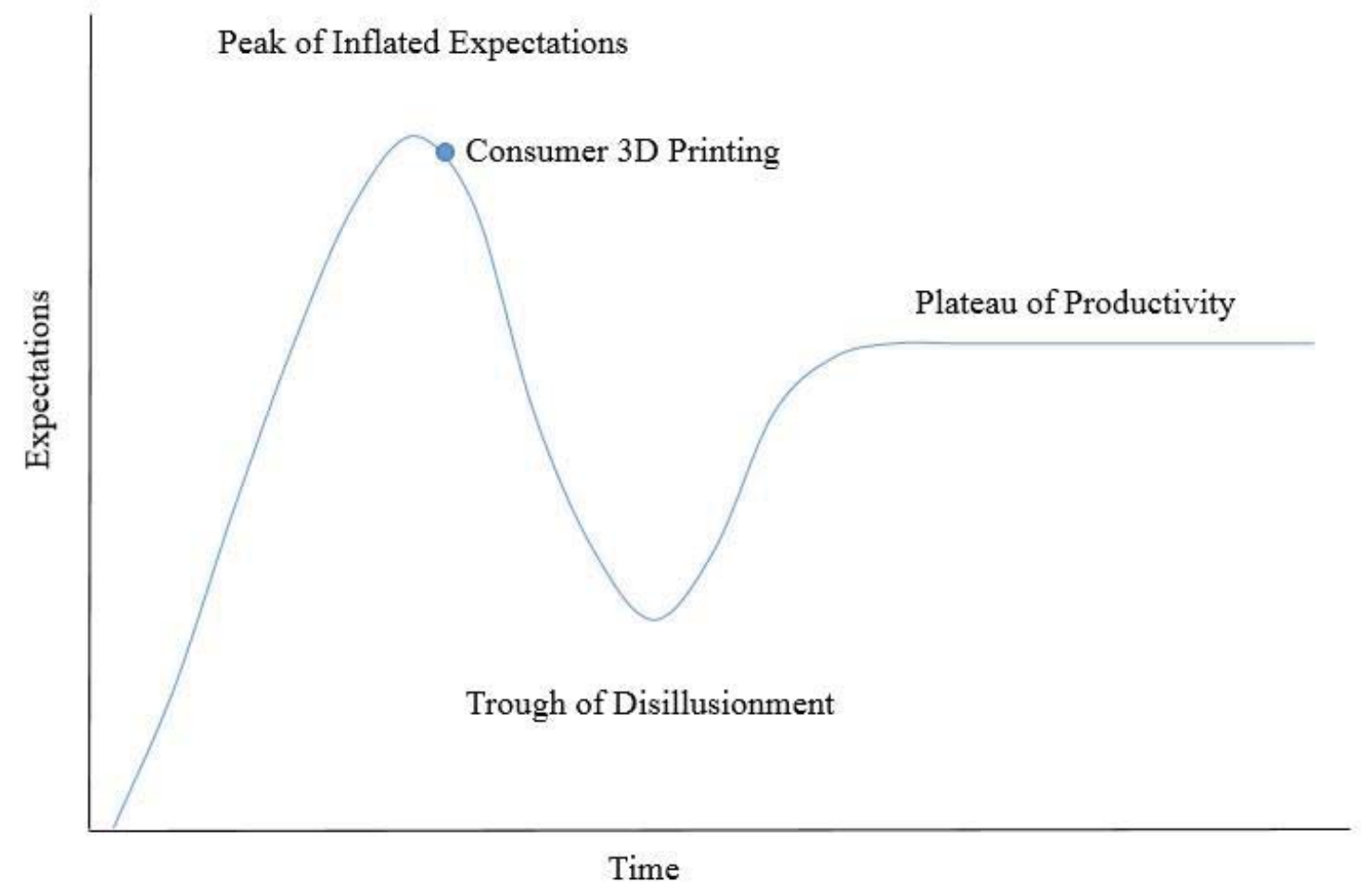

Figure 5.2: Hype Cycle for 3D Consumer Printing (Adapted from Gartner, 2014)

Understanding normative behavior within the social systems of Ghana is paramount when predicting adoption rates. A limited number of early adopters have experimented with 3D printers in Ghana and that number will only rise. Based on Gartner's predictions for consumer 3D printing and the adoption rates of other technologies in Ghana, widespread adoption of 3D printers in Ghana is likely more than ten years away. Determining the cost, quality, and output capabilities essential for a specific printer to be viable will depend on the requirements needed for a specific market and the products that are to be created. 


\subsection{Printed Products}

Understanding how 3D printers will be used require an understanding of the intended use of a printed part. The final purpose of a printed part can be divided into four major categories - (1) revolutionary, (2) evolutionary, (3) consumer-ready products, and (4) replacement parts. Revolutionary and evolutionary changes to products are done during the product design phase and require lower printing quality and accuracy. After sufficient product testing has occurred, printers are capable of direct part production for consumer-ready products and replacement parts.

\subsubsection{Product Design}

The term revolutionary when referring to innovations includes breakthroughs that are distinctly different than existing offerings and are designed for a different user group (Figure 5.3). Revolutionary breakthroughs typically take place at the precipice of research and expand outwards to new frontiers. Revolutionary innovations often occur at leading firms or institutions with well-trained professionals that have significant expertise in a specific field and have large research and design budgets. Revolutionary breakthroughs in products are relatively uncommon compared to evolutionary changes. 


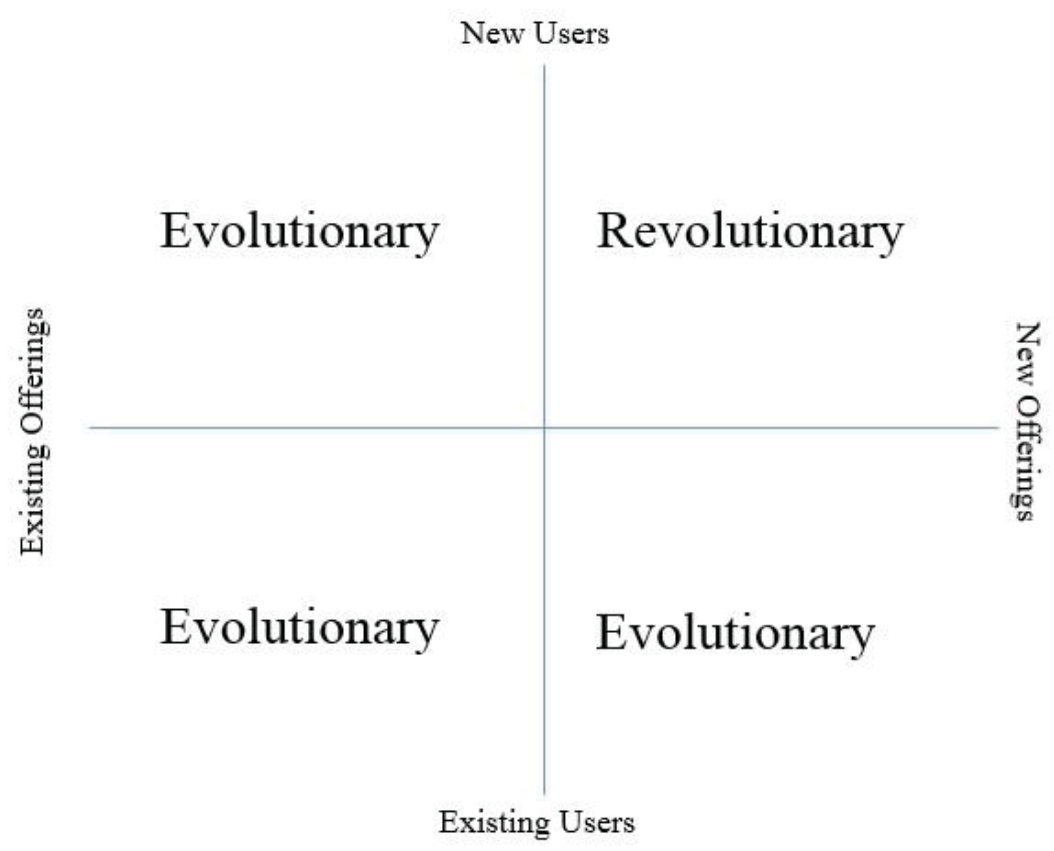

Figure 5.2: Innovation Matrix (Adapted from IDEO 2009)

Evolutionary innovations include small adaptations, iterations, or progressions that build from existing products or designs. The design firm IDEO categorizes new innovations as incremental, evolutionary, and revolutionary depending on whether innovations extend into new or existing users and offerings (Figure 5.2). This paper uses the word 'evolutionary' to represent both incremental and evolutionary innovations. Evolutionary adaptations are common during product development. Changes in the market often force companies to adapt their product offerings. Imitation is cheaper and easier than innovation. Often products are appropriate for a particular location but inappropriate in a different location because of local constraints. Slight adaptations occur to improve existing technologies or make products more appropriate for a specific market or demographic. 3D printing can deliver hyper-specific customization requests to be met through micromarketing. Changing or adapting 
existing parts requires the end-user to have advanced (CAD) capabilities. Existing CAD models may be altered to meet requests from an end user.

\subsubsection{Direct Part Production}

The phrase 'consumer-ready products' describes products that are proven successful by market pull, meaning there is a demand for the product from customers. Consumer-ready products have undergone design iterations and have reached a level of quality that is ready for user adoption. Ready-made consumer products require improved print quality and accuracy compared to prototypes. As the technology improves, 3D printers used to produce consumer ready products are expected to far surpass the current use of printers for prototyping (Wohlers, 2013).

Consumer-ready product files accessible online would allow a person who is capable of using a 3D printer to print any file that is readily available. Anyone who owned a 3D printer would, in theory, not need prior CAD or product design experience to produce a part. Products could be made to order from an existing stereo lithography (STL) file. The elimination of CAD or product design experience allows a multitude of business models to be created around owning and operating a printer. The final print quality is important and depends on both the consistency and the quality of the printer. Both the printer and the printer's settings will dictate the mechanical properties of a product. 
Replacement parts for any machine are necessary for when a breakdown occurs. When a replacement part for a particular machine is unavailable, production will cease until a completely new part is purchased. Breakdowns result in a halt in production, and can require a significant amount of time for a replacement part to arrive after being ordered. Poor infrastructure will increase the time of a shutdown because parts are more challenging to deliver. 3D printers offer the ability to overcome delivery challenges. If companies are aware of specific parts that most commonly fail in their product offerings, STL files could be provided online and replacement parts could be printed in less than a day. Replacement parts made available online by companies would facilitate maintenance and promote brand loyalty.

\subsection{Market-Oriented Ecosystem}

Pralahad (2010) emphasizes the need to develop a market-oriented ecosystem to collectively build wealth. Prahalad (2010) uses a framework that requires the private sector and social actors to coexist and complement each other to reach a dynamic equilibrium. Prahalad's (2010) ecosystem includes large local firms and multinational corporations (MNCs), small and medium enterprises (SMEs), microenterprises, extralegal enterprises, cooperatives, and non-governmental organizations. The role of governmental entities, educational institutions, makers, and entrepreneurs also play a role and may be used to further segment the ecosystem. The collaboration between all of the entities, working as nodes within the network, is important to the functionality of the overall ecosystem. All areas of a market-oriented ecosystem have the ability to benefit from 3D printing. This paper will use various institutions as examples to 
describe who may use 3D printers in different scenarios. It is understood that generalizations are being made and that specific institutions have different characteristics and approaches.

Different institutions have different printing requirements for each type of part printed, depending on the intended purpose of the print. The safe snip, maize sheller, phone cover, and 3D printer parts are given as examples of revolutionary, evolutionary, consumer-ready, and replacement parts respectively. The accuracy, quality, quantity, and speed of printing differs type of printed part. Table 5.1 compares each type of institution, printed part, and the respective printing requirements. Both revolutionary and evolutionary innovations are a result of the product design process.

\begin{tabular}{|c|c|c|c|c|}
\cline { 2 - 5 } \multicolumn{1}{c|}{} & \multicolumn{2}{c|}{ Product Design } & \multicolumn{2}{c|}{ Direct Part Production } \\
\hline Type of Part & Revolutionary & Evolutionary & Consumer-Ready & Replacement \\
\hline \multirow{2}{*}{ Institution } & $\begin{array}{c}\text { Entrepreneurs, } \\
\text { Educational } \\
\text { Institutions }\end{array}$ & $\begin{array}{c}\text { Large Local Firms } \\
\& \text { MNCs, Makers }\end{array}$ & $\begin{array}{c}\text { SMEs, } \\
\text { Entrepreneur }\end{array}$ & Micro Enterprises \\
\hline Accuracy & Low & Mid & High & High \\
\hline Quality & Low & Mid-High & Mid-high & High \\
\hline Quantity & Low & Low & High & Low \\
\hline Speed & High & Mid & Mid & High \\
\hline Example & SafeSnip & Maize Sheller & Phone Cover & 3D Printer Parts \\
\hline
\end{tabular}

Table 5.1: 3D printing requirements for product design and direct part production.

Revolutionary innovations require individuals and institutions to develop completely new offerings to different users and are likely to be made by educational institutions, entrepreneurs or research focused organizations. The necessary printing quality and accuracy is lower during the prototyping phase of product design. The SafeSnip is an example of a revolutionary product that that may be able to be 3D 
printed during the product design process. The SafeSnip is an obstetric device endorsed by USAID after winning a development design challenge that is intended to simplify umbilical cord severance and reduce neonatal mortality (Hsiao, 2014). During the product design process teams can print devices like the SafeSnip to refine their idea and test prototypes quickly. Small startups employ different approaches to existing methods and are able to quickly adapt to disrupt existing enterprises with new innovations or approaches. The number of start-ups and entrepreneurs in Ghana is growing (WRI, 2007).

Evolutionary innovations require less dramatic changes to an existing product and are more appealing to large local firms or multinational corporations who are more risk adverse. Large local firms and multinational corporations (MNCs) have large budgets and are well positioned to try new approaches to grow through diversification and to open up new markets. MNCs are most likely to utilize 3D printed products for evolutionary adaptations or for replacement parts; however it depends on the company's strategic plan. Designing for the most underserved markets require a different approach than designing for an affluent consumer base. For example, a company may already offer agricultural implements but wants to start selling handheld maize shellers. The company may be able to use a 3D printer to produce adaptations of existing maize shellers with a 3D printer and gather feedback from users who have field tested the maize sheller. Testing a 3D printed maize sheller in the field requires a working prototype with moderate print quality and accuracy. Based on feedback the company could continue to alter the design. Companies realize the opportunity for investment in emerging markets though they have often struggled to penetrate 
underserved markets while making a profit. Many companies recognize the need for lower-cost offerings and provide less for less (Eyring et al., 2011).

Individuals who personally make a product because there is not a suitable product available can be considered a maker. Makers are characterized by their ability to tinker and make objects of their desire. The maker movement broadly consists of a community committed to a do-it-yourself mentality that works through a collaborative exchange of ideas (Anderson, 2012). CAD software may be used to develop a new maize sheller that fits the local maize variety. Makers are likely to be creating evolutionary products during product design stage.

Consumer-ready products printed at a corner shop or within a household require the printing capabilities and consistency to match the requirements for a particular product. The idea of consumer 3D printing at a service bureau at any corner shop around the world offers many possibilities. Entrepreneurs are well positioned to take advantage of the disruptive nature of 3D printing and create a business around a product or a printer. Similarly, small to medium enterprises (SMEs) and micro enterprises are more capable of pivoting their strategic plan compared to larger companies and may be able to utilize a 3D printer or printed products to gain a competitive advantage. Small and Medium Enterprises (SMEs) are a disproportionate percentage of the economy in Ghana and other emerging economies (Ayygari et al., 2003). Currently, the printing capabilities of low cost 3D printers are inhibiting the use of printers for widespread direct part production. A personalized phone cover is offered as an example of a product that a low-cost printer can meet the necessary 
requirements for an on-demand printing service. Many of the widgets found in online 3D printing databases are relatively low-tech, similar to a cell phone case, however as 3D printing technology improves the array of available products will increase.

3D printed replacement parts require high quality prints made accurately to the design file. The speed in which a replacement part can be created is a leading benefit of 3D printing over ordering a part and minimizing the time for a breakdown. Many replacement parts for RepRap 3D printers are available online and can be printed. If a part on the printer breaks a new one can be printed and will minimize the time when production is stopped. If replacement parts are available on line for a wide variety of machines the cumulative impact of 3D printers will increase.

\subsection{Location of Individuals and Institutions}

Urban centers provide a larger market for goods and services. Internet and electricity quality are often higher compared to more remote settings. There is often a higher population of educated individuals and more diverse economic activity. Rural areas often have limited access to goods, services, and poor infrastructure that leads to limited access to markets. Underserved markets are characteristically rural in Africa (WRI, 2007). 3D printers are uniquely positioned to serve rural communities because of the limited infrastructure requirements.

The consulting firm, Accenture, used personas to represent the Five Key SubSaharan African Consumer Segments to gain a better understanding of the consumers and where they are located. The lowest income segment is the 'basic survivors', which 
is the largest segment. Members typically live in urban slums or rural areas and make most purchases based on basic needs. Second is the 'working family' segment, which is the second largest segment and members make purchases based on both basic needs and family demands. Working families can be found in a variety of locations. Next is the 'rising strivers' segment, which is differentiated from the previous two segments in that there is more disposable income to be spent and an aspiration for upward mobility. Rising strivers are often urban migrant workers or have benefited from a rurally based industry or business. Many rising strivers are still a part of the base of the economic pyramid, however some have moved up to the mid-market segment. The remaining two consumer segments are the 'cosmopolitan professionals' and the 'affluent'. The final two segments are not part of the bottom of the economic pyramid however the segments should be taken into consideration for any business entering a market in SSA.

\section{Chapter 6 Implementation of 3D Printing}

Several considerations must be taken into account when introducing a new technology into a market. Initiating a 3D printing ecosystem will require printers to be introduced on a limited basis to undergo market testing and gain consumer feedback. As 3D printers demonstrate success within a specific market, the printed products may be introduced to elicit consumer responses. After both 3D printers and 3D printed products have proven to be successful, market expansion may occur to scale impact and increase profits. The histories of other technologies are given as an example to speculate how 3D printers may be implemented. 


\subsection{Introducing 3D Printers}

Deciding exactly how to implement a 3D printing ecosystem is difficult due to the complexity of the products, markets, and stakeholders involved. Further market segmentation may be necessary to target specific consumers. Implementation should be context dependent. Similar methods that are used when a business enters a new market may be used, though special considerations must be taken into account when entering the most underserved markets. Certain infrastructure requirements must be in place to operate 3D printers. The introduction of cell phones and computer software are presented as a basis for how 3D printers and software might be introduced in the future.

If the average selling price of does not meet the minimum threshold for a particular market, no other printer characteristics will matter. Assuming the price is appropriate for a particular market, the overall functionality and quality of printers will be the next most critical aspect. If there is a gap between the promise of a 3D printer and the reality of its capabilities, there is the risk that a breakdown of trust will occur and consumers may lose faith in the technology. If opinion leaders within an industry or community lose faith in 3D printers, it will become more difficult for the technology to penetrate that particular market in the future.

The successes of mobile phones in SSA is well documented (Aker and Mbiti, 2010). Studies show that adoption rates of mobile phones correlate with job creation and increased GDP (Brookings). The early adopters of mobile phones were male, educated, young, wealthy, and urban populations, while all other demographics 
including the early majority and late majority followed soon after (Bhavnan, Chiu, Janakiram, and Silarszky, 2008). Firms adopted mobile phones prior to individuals because of the ability to improve efficiency and manage supply chains (Bhavnan et al., 2008). Thus, the users perceived mobile phones as an income-generating technology. Firms that are able to use 3D printers as an income-generating technology must be identified. One might conclude that there will be a similar demographic of early adopters for 3D printers due to educational and socioeconomic conditions.

A number of lessons can be learned from the introduction and evolution of the personal computer industry that can be applied to the introduction of 3D printers. Anderson (2009) discusses how companies have competed with free offerings in the past and how they might profit from free in the future. In the 1990s, Microsoft was concerned with how their software that costs thousands of dollars to develop was being copied and distributed freely. Security codes and lawsuits were able to keep piracy subdued within advanced economies but piracy remained uncontrollable within emerging markets (Anderson, 2009).

The difficulty of eradicating piracy was understood and thus creative methods were devised to profit off of pirated software. Free versions of Microsoft's software created a dependency and accelerated adoption rates in large valuable markets such as China. After creating a dependency on Microsoft's software, consumers with more money became tired of difficulties related to pirated software and were willing to pay for authorized software (Anderson, 2009). The availability of pirated or free open source software for computer aided design (CAD), slicing, and printing will increase 
usage and expedite adoption rates in Ghana and other emerging markets. Companies will need to find creative business models that are able to profit off of the 3D printing ecosystem. Autodesk released the first professional open source 3D printing platform, Spark, in 2014. "Spark will offer a set of industry standards for all aspect of the 3D printing ecosystem: software, hardware, materials, and services" (http://spark.autodesk.com/about, para 2). According to Carl Bass, CEO of Autodesk, Spark will use a business model similar to Google's Android. Just as Android used an open source strategy to become the leading mobile and tablet operating system, Spark intends to use an interoperability and open source strategy to become the leading 3D printing platform (Bloomberg, 2015). Other competing businesses and open source software providers will compete for market share as 3D printing technologies mature.

\subsection{Introducing Printed Products}

3D printed products must undergo rigorous testing similar to other products that are being introduced into underserved markets. Methodologies used when designing and introducing existing products for the bottom of the pyramid should also be applied to 3D printed products. An increased number of products are being developed due to increased interest from the international design industry (Whitehead et al., 2014). For example, Polak (2008) outlines what is called Practical Steps for Design for the Other 90 Percent. The design firm IDEO promotes a Human Centered Design Toolkit (IDEO, 2011) that emphasizes feasibility, viability, and desirability. Designing products for underserved markets requires designers to take a different approach to the product development. Castillo et al. (2012) aggregated four leading approaches for 
designing for the bottom of the pyramid (BOP) and developed a methodological framework and tools for the BOP (Castillo, et al., 2012).

Many of the texts and toolkits that emphasize the importance of empathy and user feedback can be utilized as a resource. Successful products require specific considerations for a given product, market or context. Co-creation and co-design software for 3D printing is currently available and allows users to modify drawings by moving slide bars or entering text (Wohlers, 2013). Simplified software demonstrates how 3D printing technologies may improve the design process for underserved markets.

Specific questions should be asked when determining whether products should be printed.

- How do 3D printed products compare to products made from existing processes?

- Can the value to cost ratio be increased thorough 3D printing or customization?

- What are the profit margins?

- Can material waste be reduced?

- What are the technical requirements related to loading or fatigue?

- Are replacement parts available for plastic products?

- Is plastic perceived as durable or reliable?

- What are the social considerations and perceptions?

- Is there a comparable product that demonstrates demand?

- Are there quality concerns with durability or reparability? 
The pressures of group conformity are especially high in low-context cultures such as Ghana (Hall, 1976). New products may be thwarted when individuals are rewarded for conformity and conversely punished for individuality (Callero, 2013). Other factors that affect social capital and social cohesion must be considered when determining desirability of newly introduced 3D printed products.

\subsection{Scaling 3D Printers}

The challenges related to scaling 3D printers effectively may include existing political and power structures, poor infrastructure (electricity and Internet bandwidth), communication breakdowns, information gaps, and the requisite knowledge capital necessary for the operation of all aspects of the 3D printing process. Mobile phones are offered as an example of how a technology can overcome scaling and infrastructure challenges while the web server market is presented to forecast the role that open source and proprietary business models may have within the 3D printing industry.

Mobile phones are often used as a source of optimism to demonstrate how a technology can experience rapid adoption within SSA. Research was conducted on mobile phones to discover the determinants of adoption. Mobile phone coverage and adoption rates are not uniform throughout SSA. The telecommunications industry directed the growth of coverage by assessing potential demand. Strategic decisions were influenced by population density, per capita income and the competitiveness within the mobile phone market of each country (Bhavnan et al., 2008). 
The web server market offers another example of how the 3D printing market may solidify in the future with respect to open source and proprietary software and hardware. Initially, Microsoft dismissed Red Hat Linux's open-source business model until it started seizing market share and cutting into revenues. After conceding $20 \%$ market share, Microsoft accepted a position of interoperability with open source software. There is currently a place within the web server market for free software, free software with paid support, and paid software with paid support (Anderson, 2009). Makers, entrepreneurs, extralegal entities, microenterprises, and SMEs generally lack large capital resources and prefer free open source options. Large Enterprises, MNCs, and governmental agencies are risk-averse and are willing to pay for service level contracts to minimize downtime if problems arise (Anderson, 2009). As a nascent industry, the 3D printing market has begun to segment itself with various free and paid software packages available. As the competition for revenue and market shares increase, the quality and price of available software packages will also improve. 3D printing will become more accessible and spread faster as the software integration becomes more streamlined.

The social pressures of group conformity within high-context cultures may become a benefit during the scaling process. If 3D printers overcome a certain threshold of acceptance, firms and individuals may begin to imitate others, which will accelerate adoption. Reaching a threshold of general acceptance is the difficult aspect of scaling any technology in Ghana. The chasm within the technology adoption lifecycle and luddites (people who stymie all new technology) will always be present and 
slow adoption. Again, other factors that affect social capital and social cohesion must be considered when attempting to scale 3D printers.

\subsection{Scaling Printed Products}

The ability to bring functional products to scale is necessary to both achieve substantial impact and for businesses to be sustainable. Risks and barriers associated with scaling printed products exist, although a 3D printing ecosystem is uniquely positioned to overcome existing barriers commonly associated with bringing a product to scale. A 3D printing ecosystem can scale products at unprecedented rates by enabling the benefits of both a digital and a networked economy. The limitations of 3D printed products are likely to be a challenge when scaling products in the future. Efforts to scale 3D printed products will be futile unless the products are proven as beneficial.

Polak (2008) argues that if a product cannot be scaled up systematically to reach at least a million customers it is not worth implementing due to the inability to have widespread impact. Products are evaluated on their ability to reach transformative scale. Success will be determined by the objectives set by specific enterprises. Replication is cheaper and faster than innovation. Scaling products within a 3D printing ecosystem generates unprecedented possibilities when attempting to overcome scaling difficulties. A product's ability to scale and demonstrate impact is vital to investors and funding agencies. Often, focusing on scaling proven solutions is more important than discovering the next great idea (IDEO, 2011). 
Utilizing the digital economy for direct part production allows products to overcome many remote delivery challenges. Creating products from digital information eliminates the dependence on intermediaries and associated transportation costs. 3D printing is reliant on costs related to Internet, electricity, filament, and servicing, which are all less volatile compared to the external shocks of fuel shortages and corruption experienced along complex supply channels. Minimizing uncertainty will reduce the cost of conducting business. Scaling is cheaper and faster when a technology makes it possible for companies to make geographic boundaries irrelevant and minimize the need for physical space intended for inventory storage.

As 3D printing matures there will be increased attention on 3D scanning, ownership of CAD drawings and intellectual property concerns. 3D printing may experience similar challenges that the software industry faced in the 1990s. Anderson (2009) states that within the Internet economy, information often becomes cheaper because digital information can be easily reproduced. Anderson (2009) argues that information is subject to the laws of supply and demand where "abundant information wants to be free" and "scarce information wants to be expensive". 3D printable design files are electronic files consist of information and can freely be transferred electronically. If design files become abundant and can be transferred freely, physical objects may also become practically free.

Before product design files can be released for distribution there must be a certification process to determine which designs are in the product development phase. A lack of interoperability within CAD files, detailed model simulation (finite element 
analysis), slicing, and printing software, which remains cumbersome for designers and engineers interacting within the 3D printing ecosystem. The entire process must be simplified to expedite and encourage engineering services for 3D printed products. The process from idea to creation must become streamlined if the technology is to become more accessible (Wohlers, 2013). The software and printing process is currently too complex for many consumers. Fundamental to the excitement surrounding 3D printing is that anything can be imagined by anyone and then can be turned into a physical object at the click of a button. Many 3D printing companies understand the reality that a gap between imagination and production remains and are moving towards making the creation of 3D printed products as simple as pressing a print button (Rotman, 2013). As the 3D printing process becomes simplified the barriers to entry may be reduced and larger demographics of people may become involved in the making process.

\section{Chapter 7 Discussion and Conclusions}

This report investigated how 3D printers could be used to create improved products for the most underserved markets within Ghana. The necessary conditions for economic development were determined by researching the effects of different development approaches. The links between economic growth, economic development, and the advancement of technology were detailed within the historical context of Ghana. Based upon these economic development conditions and the historical context of technology and growth, the opportunities for 3D printing to penetrate underserved markets was then presented. Next a series of questions were asked to determine the role that 3D printers may play within Ghana. Why are 3D 
printers important? What are the current barriers to adoption and when might adoption occur in the future? Who will create what types of products, and how might the products be used? How can 3D printers and the 3D printed products be introduced and scaled for impact? This set of questions was intended to establish a foundation upon which a market-based approach to 3D printers for economic development may be applied and studied with more depth.

\subsection{Conclusions}

Considering the ineffectiveness of many developmental approaches, a marketbased approach is presented for poverty reduction. A market-based approach relies upon success with end users and customers to determine the value of a product, service, or technology. Businesses can use market forces to improve the living conditions of those in poverty by delivering products and services to those in poverty. The most underserved markets are currently underserved because the markets are perceived to be risky and nearly impossible to make a profit. An effective business ecosystem will spur economic activity and create wealth. Businesses models must be designed to produce products and services that cater to the mid-market segment and the bottom of the economic pyramid that are valued at \$12.5 trillion and \$5 trillion, respectively. Opportunities for market entry exist and market feedback will drive companies to find creative ways to expand offerings and grow a customer base. As one of Africa's fastest growing economies, Ghana has the ability to serve as an effective proving ground for new technologies and businesses that aim to both generate a profit and improve the standards of living for many. 
The advancement of 3D printers must be leveraged in Ghana. Technological advancement is inexorably linked to economic development and is required for an increase in production per person. Making technological advancements available to everyone across an economy can significantly lessen socioeconomic stratification. 3D printers may possibly be just such an advancement. 3D printers have demonstrated an ability to disrupt existing industries by allowing new products to be created at a faster rate than previously possible. 3D printers excel at rapid prototyping, reducing lead times, reducing overhead, and mass customization. The recent drop in price of 3D printers has made the technology more accessible to a broader base of users. Low-cost personal 3D printers for $\$ 3,000$ make the technology more accessible for Ghanaian businesses. A significant gap exists between the price and capabilities of industrialgrade 3D printers and personal 3D printers. The capabilities of industrial-grade printers are often well publicized, while the realities of personal 3D printers are often overlooked. Personal 3D printers continue to be a complex piece of machinery that prints inconsistently, with failure rates of prints between 25\% and 70\% (Kowalski, 2014). Barriers to adoption in Ghana exist and improvements must be made in the hardware, software, and materials used in low-cost printers. The hardware used in printers require regular manual maintenance to ensure proper calibration. The software integration and workflow of 3D printing remain cumbersome. Most low-cost 3D printers are restricted to a couple types of plastic. Low-cost 3D printers must improve overall performance, print a wider array of materials, and produce consumer-ready products. Both businesses and consumers will dictate how 3D printers are adopted based on printing requirements and performance needs. 
Adoption of 3D printers and printed products will be subjected to the basic diffusion model that new innovations and ideas follow. The first two groups in the diffusion model are the innovators and early adopters groups who are likely to be located in urban areas within the 'rising strivers' and 'cosmopolitan professionals' demographics. Companies and technologies often fail when crossing the chasm between the early adopters and the early majority. To be successful, a company must focus on a single niche market to cross the chasm to reach the mainstream market. As printers and products are proven successful in specific markets, the cumulative impact will expand when the technologies are brought to scale.

The impact of 3D printing in Ghana is dependent on both the technology's ability to add value and business' ability to develop strategies to overcome existing barriers to adoption. As the technology matures, market acceptance will determine if 3D printers and 3D printed products are valued. 3D printers must be perceived as a profit generating technology. If 3D printers and products do not meet all of the needs of the market, the technology will only add to the innumerable pieces of derelict machinery found in Ghana. The demand for a prototyping tool may be limited in Ghana due to the few number of businesses designing products for underserved markets. As the technology improves it may no longer be used predominately as a prototyping and product design tool and become a localized manufacturing machine used for direct part production. Given the state of the art of low-cost 3D printers and the business conditions in Ghana, widespread market penetration of 3D printers and 3D printed parts in Ghana is estimated to be at least ten years away. 


\subsection{Broader Impacts}

Few companies have considered how to implement 3D printers for development purposes. The outcome of this report was a framework to help determined how 3D printers might best be leveraged for economic development in Ghana. The marketbased approach presented may be applied not only to 3D printers but also to any new technology being introduced to underserved markets in Ghana or elsewhere. In particular, it is hoped that people will consider a wider view of how 3D printing fits within the historical context and complexities of the social sciences, developmental economics, technological advancement, innovation theory, business, marketing, entrepreneurship, and engineering product design.

\subsection{Further Study}

This report was an initial investigation into understanding the market-based forces for the introduction of 3D printers. Given the popularity of 3D printers, it was surprising how little attention was given to previous successes and failures of development approaches when determining how 3D printers might best be applied for poverty reduction in the most underserved markets. This report opens up opportunities for further studies of 3D printers and 3D printed products in a variety of disciplines, including:

- Use human-computer interaction methods to develop ways to simplify the printing process.

- Diversify materials.

- Increase the speed and reliability. 
- Develop a methodology that integrates human-centered design

- Identify social dynamics affecting the diffusion in underserved markets.

- Employ systems thinking to the market-based approach to the 3D printing ecosystem.

While daunting, the multidisciplinary needs demonstrate the importance of and opportunity for collaboration. Utilizing a systems thinking process to 3D printer development will allow for a more holistic understanding of how the disciplines interact. It is imperative to comprehend the relationship between the various fields of study mentioned earlier and recognize how the confluence of knowledge can be used to actualize the potential of 3D printing technology to benefit humanity. Ultimately, the success and progress of society as a whole depends on the dedicated actions of individuals. Just as 3D printers move towards realizing their promise of transforming ideas into tangible objects, individuals must transform their ideas into tangible actions. 


\section{References}

Acemoglu, D., \& Robinson J. (2012. Why Nations Fail: The origins of power, prosperity and poverty. New York Crown Publish Group.

Anderson, Chris. 2012. Makers: The New Industrial Revolution. New York: Crown Publishing Group.

Aker, J. C., \& Mbiti I. M. (2010, Summer) Mobile phones and economic development in Africa. Journal of Economic Perspectives, 24(3), 207-232. Retrieved from http://sites.tufts.edu/jennyaker/files/2010/09/aker_mobileafrica.pdf

Banerjee, A., \& Duflo, E. (2012). Poor economics: A radical rethinking of the way to fight global poverty. New York: Public Affairs. doi:9781610390934

Barro, R. J., \& Sala-i-Martin, X. I. (2004). Economic growth (2nd ed.). Boston: MIT Press.

Birtchnell, Thomas, and William Hoyle. 2014. 3D Printing for Development in the Global South: The 3D4D Challenge. New York: Palgrave Macmillian.

Berman, B. (2012, March-April). 3-D printing: The new industrial revolution. Business Horizons, 55(2), 51-60.

Bass, C. (2015). Video interview with C. Bass. Bloomberg.com. Bloomberg: New York. Retrieved from http://www.bloomberg.com/news/videos/b/1a5ea85f43dc-4dc2-a2a6-440779c26e48

Brookings Institution (n.d.) Mobile technology. Washington, DC: Brookings Institution. Retrieved from 
http://www.brookings.edu/ /media/press/books/2014/going-mobile/chapterone.pdf

Callero, Peter L. 2013. The Myth of Individualism: How Social Forces Shape Our Lives. Lanham: Rowman \& Littlefield .

Castillo, L. G., Diehl, I. J. C., Brezet, J. C. (2012). Design considerations for base of the pyramid (BoP) projects. Conference Paper Cumulus 2012, Helsinki. Retrieved from http://www.researchgate.net/publication/257927083_Design_Considerations_fo r_Base_of_the_Pyramid_(BoP)_Projects

Collier, Paul. 2007. The Bottom Billion Why the Poorest Countries are Failing and What Can Be Done About It. New York: Oxford University Press, Inc.

Comin, D., Easterly, W., \& Gong, E. (2010, July). Was the wealth of nations determined in 1000 BC? American Economic Journal: Macroeconomics, 2, 65-97. http://www.aeaweb.org/articles.php?doi 10.1257/mac.2.3.65

Downes, Larry, and Paul Nunes. 2014. Big Bang Disruption Strategy in the Age of Devastating Innovation. New York: Penguin Group LLC.

Easterly, William. 2001. The Elusive Quest for Growth: Economists' Adventures and Misadventures in the Tropics. New York: The Penguin Press.

Easterly, William. 2006. White man's Burden Why the West's Efforts to Aid the Rest Have Done so Much Ill and so Little Good. New York: The Penguin Press. 
Edgerton, David. 2007. The Shock of the Old: Technology and Global History Since1900. New York: Oxford University Press, Inc.

Ferguson, James. 1990. The Anti-Politics Machine: "Development," Depoliticization, and Bureaucratic Power in Lesotho. Minneapolis: Cambridge University Press.

International Development Research Centre. (2012). Understanding what is happening in ICT in Ghana. Cape Town: Godfred Frempong.

Ishii, Kazuya. 2001. The Socioeconomic Thoughts of Mahatma Ghandhi: As an Origin of Alternative Development. Review of Social Economy, 59.3, 297-304.

Kowalski, J. (2014). 3dprintingindustry.com. New York: Retrieved from http://3dprintingindustry.com/2014/10/22/autodesk-svp-jeff-kowalski-3dprinting-kind-sucks-right-now/

Hatch, G., Becker, P., van Zyl, M. (2011). The Dynamic African Consumer Market: Exploring Growth Opportunities in Sub-Saharan Africa. Accenture. Retrieved from http://www.accenture.com/sitecollectiondocuments/local_south_africa/pdf/acce nture-the-dynamic-african-consumer-market-exploring-growth-opportunities-in$\underline{\text { sub-saharan-africa.pdf }}$

Hattingh D., Russo, B., Sun-Basorun, A., Van Wamelen, A. (2012, October). The rise of the African consumer: A report from McKinsey's Africa Consumer Insights Center. McKinsey \& Company. Retrieved from 
http://mckinseyonmarketingandsales.com/sites/default/files/pdf/The_Rise_of_th e_African_consumer.pdf

Holmstrom, J., Partanen, J., Khajavi, S. (2014). Additive manufacturing in the spare parts supply chain. Computers in Industry, 65.1, 50-63.

Landrum, N. E. (2007). Advancing the "Base of the Pyramid." Strategic Management Review, 1(1). Retrieved from http://www.academia.edu/1350051/Advancing_the_base_of_the_pyramid_deba te

MapCruzin. (2007). Ghana (Political) 2007. Retrieved from http://www.mapcruzin.com/free-ghana-maps.htm

Meredith, Martin. 2011. The State of Africa. London: Simon \& Schuster UK Ltd.

Hsiao, T. H., Casey, A. (2014). U.S. Global Development Lab, The Catalog Version 1.5. Retrieved from http://www.usaid.gov/sites/default/files/documents/15396/USAID_Lab_The_Ca $\underline{\text { talog_V1_5.pdf }}$

Mokyr, J. (1990). The Lever of Riches: Technological Creativity and Economic Progress. New York: Oxford University Press.

Michalopoulos, S., \& Papaioannou, E. (August 2012). National institutions and subnational development in Africa NBER Working Paper No. w18275. Retrieved from http://ssrn.com/abstract=2123014

Moore, G. (2014). Crossing the Chasm, $3^{\text {rd }}$ Edition: Marketing and Selling Disruptive Products to Mainstream Customers. New York: Harper Business Essentials. 
Moyo, D. (2009). Dead aid: Why aid is not working and how there is another way for Africa. New York: Farrar, Straus and Giroux.

Naylor, Rachel. 2000. Ghana. London: Oxfam GB.

Papanek, Victor. 1971. Design for the Real World. Chicago: Academy Chicago Publishers.

Polak, Paul. 2008. Out of Poverty: What Works When Traditional Approaches Fail. San Francisco: Berrett-Koehler.

Perkins, D. H., Radelet, S. C., \& Lindauer, D. L. (2006). Economics of development. New York: W.W. Norton.

Prahalad, C. K. 2006. The Fortune at the Bottom of the Pyramid. Upper Saddle River: Pearson Education, Inc.

Robinson, James A., and Daron Acemoglu. 2012. Why Nations Fail The origins of Power, Prosperity, and Poverty. New York: Random House, Inc.

Rogers, E. M. (2003). Diffusion of Innovations, Fifth Edition. New York: Free Press.

Rotman, D. (2013, January/February). The difference between makers and manufacturers. Technology Review: MITs Magazine of Innovation, 116(1), 7678.

Sachs, J. D. ( 2005). The End of Poverty. New York: Penguin Press.

Sen, Amartya. 1999. Development as Freedom. New York: Alfred A. Knopf, Inc.

Schumacher, E. F. (1973). Small is beautiful: A study of economics as if people mattered. New York: Harper. 
Stiglitz, J. E., \& B. C. Greenwald, B. C. (2014). Creating a learning society: A new approach to growth, development, and social progress.

New York: Columbia University Press. Doi:978-0-231-15214-3

The Hague. (2013). African consumers: Driving the African private equity opportunity. The Hague, The Netherlands: FMO Fairview.

Thomas, D. S., \& Gilbert, S. W. (2014, December). Costs and cost effectiveness of additive manufacturing: A literature review and discussion. NIST Special Publication 1176. National Institute of Standards and Technology, US Department of Commerce. Retrieved from http://dx.doi.org/10.6028/NIST.SP.1176

USAID, DFID. (2012). USAID, DFID highlight millennium development goal progress. Retrieved from http://www.usaid.gov/news-information/pressreleases/usaid-dfid-highlight-millennium-development-goal-progress

Van der Klein, W., Mancheron, H., Wetheim-Heck, S., \& Collee, L. (2012, November). BoP insights: Inclusive marketing research. Three Pilots for ProPoor Innovation Consortium. The Netherlands: BoP Innovation Center.

Verganti, R. (2009). Design-Driven innovation: Changing the rules of competition by radically innovating what things mean. Boston: Harvard Business Press Books.

Waldman-Brown, A., Obeng, G. Y., Adu-Gyamfi, Y., Langevin, S., \& Adam, A. Fabbing for Africa's informal sector. Zeist, The Netherlands: International Fab Lab Association. http://www.fablabinternational.org/ 
Wohlers, R., \& Gomez, T. (2013). History of additive manufacturing. Wohlers Report 2013. Fort Collins, CO: Wohlers Associates, Inc.

Wohlers, R. (2013). Wohlers Report 2013 Additive Manufacturing and 3D Printing State of the Industry Annual Worldwide Progress Report. Wohlers Report 2013. Fort Collins, CO: Wohlers Associates, Inc.

World Bank Group. (2014). Mobile at the base of the pyramid: Ghana. InfoDev Growing Innovation. Washington, DC: www.infoDev.org, iii-39.

Yunus, M. (2003). Banker to the poor: Micro-lending and the battle against world poverty. New York: Public Affairs. doi:978-1-58648-198-8

Yunus, M. (2007). Creating a World Without Poverty. New York: Public Affairs.

Zollmann, J. (2014, August). Kenya financial diaries: Shilingi Kwa Shilingi-The financial lives of the poor. Kenya: Financial Sector Deeping (FSD Kenya). 